\title{
StreptInCor, a Group A Streptococcal Adsorbed Vaccine: Evaluation of Repeated Intramuscular Dose Toxicity Testing in Rats
}

\section{OPEN ACCESS}

Edited by:

Kadaba Sriprakash,

QIMR Berghofer Medical Research

Institute, Australia

Reviewed by:

Manisha Pandey,

Griffith University, Australia

Natkunam Ketheesan,

University of New England, Australia

${ }^{*}$ Correspondence: Luiza Guilherme luizagui@usp.br

Specialty section:

This article was submitted to

Heart Valve Disease,

a section of the journal

Frontiers in Cardiovascular Medicine

Received: 17 December 2020 Accepted: 22 March 2021

Published: 11 May 2021

Citation:

de Sá-Rocha LC, Demarchi LMMF Postol E, Sampaio RO, de Alencar RE,

Kalil J and Guilherme L (2021)

StreptInCor, a Group A Streptococcal

Adsorbed Vaccine: Evaluation of

Repeated Intramuscular Dose Toxicity

Testing in Rats.

Front. Cardiovasc. Med. 8:643317.

doi: 10.3389/fcrm.2021.643317

\author{
Luiz Carlos de Sá-Rocha ${ }^{1}$, Lea Maria Macruz Ferreira Demarchi ${ }^{2}$, Edilberto Postol ${ }^{2,3}$, \\ Roney Orismar Sampaio ${ }^{2}$, Raquel Elaine de Alencar ${ }^{2,3}$, Jorge Kalil2,3 and \\ Luiza Guilherme ${ }^{2,3 *}$
}

${ }^{1}$ Neuroimmunology Laboratory School of Veterinary Medicine and Animal Sciences, University of São Paulo, São Paulo, Brazil, ${ }^{2}$ Heart Institute (InCor), School of Medicine, University of São Paulo, São Paulo, Brazil, ${ }^{3}$ Immunology Investigation Institute, National Institute for Science and Technology, University of São Paulo, São Paulo, Brazil

Streptococcus pyogenes infections continue to be a worldwide public health problem, causing various diseases in humans, with rheumatic fever and rheumatic heart disease being the most harmful manifestations. Impetigo and post-streptococcal glomerulonephritis are also important sequelae of skin infections. We have developed a candidate vaccine epitope (StreptInCor) that presents promising results in diverse animal models. To assess whether the StreptInCor alum-adsorbed vaccine could induce undesirable effects, a certified independent company conducted a repeated intramuscular dose toxicity evaluation in Wistar rats, a choice model for toxicity studies. We did not observe significant alterations in clinical, hematological, biochemical, anatomical, or histopathological parameters due to vaccine administration, even when the animals received the highest dose. In conclusion, repeated intramuscular doses did not show signs of macroscopic or other significant changes in the clinical or histopathological parameters, indicating that StreptInCor can be considered a safe candidate vaccine.

Keywords: S. pyogenes, vaccine, safety, histopathology, toxicity

\section{INTRODUCTION}

Streptococcus pyogenes, also known as group A streptococcus (GAS), is a Gram-positive bacterium responsible for some human diseases, such as pharyngitis, impetigo, and post-streptococcal complications, including glomerulonephritis and rheumatic fever (RF) and severe sequelae of rheumatic heart disease (RHD). The highest incidence of infections by GAS occurs in children between 5 and 15 years of age, especially in children living in poor sanitation conditions (1). Bowen et al. performed a systematic review and estimated that more than 162 million children younger than 15 years had impetigo and the broader condition pyoderma in low-income and low-middle-income countries (2). A meta-analysis study conducted by Shaikh et al. estimated that the prevalence of GAS infection among children of all ages who present with sore throat was $37 \%$, and in those younger than 5 years, it was $24 \%$. The prevalence of GAS carriage among well children with no signs or symptoms of pharyngitis was $12 \%$ (3). A recent study reported the occurrence of $\sim 319,000$ deaths from RHD-related complications. Although the health-related burden of RHD has declined worldwide, high disease rates persist in the world's poorest regions (1). 
RF generally develops after the occurrence of untreated streptococcal pharyngitis and affects $\sim 0.3-3 \%$ of susceptible individuals. Among the manifestations of RF, RHD is the most important sequelae and affects $45 \%$ of RF patients, and it is capable of causing serious damage to the aortic and mitral valves, leading to cardiac dysfunction (4). In Brazil, RHD accounts for $90 \%$ of cardiac surgeries in children (5).

Although not fully elucidated, RF/RHD develops from the involvement of autoimmune mechanisms mediated by molecular mimicry in genetically predisposed individuals. Genetic susceptibility is related to several gene polymorphisms of placebo innate and adaptive immune responses (6-8).

In the case of RHD, the activation of T and B lymphocytes may lead to the production of antibodies and $\mathrm{T}$ lymphocytes reactive against some epitopes of the $\mathrm{N}$-terminal region of the $\mathrm{M}$ protein, which may react against myocardial and valvar tissue proteins due to their similarity to pathogen epitopes (9-13).

GAS strains are currently identified by sequencing the hypervariable $\mathrm{N}$-terminal region of the $\mathrm{emm}$ gene encoding the $M$ protein, and they have already been classified into more than $220 \mathrm{emm}$ types, with some identified as rheumatogenic strains (14-16). These findings suggest that not all strains contain the epitopes capable of triggering RF/RHD but are probably involved with other manifestations, such as impetigo or glomerulonephritis.

Since the pioneering studies conducted by Rebecca Lancefield in 1962, the $M$ protein has been the target of choice for a streptococcal vaccine (17). The M protein is formed by two coilcoiled chains with a flexible structure located on the bacterial wall and represents an important virulence factor that is highly immunogenic. Unlike the polymorphic $\mathrm{N}$-terminal region of the $\mathrm{M}$ protein, the C-terminal region is highly conserved among the different serotypes $(15,18)$.

Vaccines based on both the $\mathrm{N}$ - and C-terminal regions of the $\mathrm{M}$ protein have been proposed in the last 14 years using new technologies, such as recombinant proteins or synthetic peptides (19-22).

The present work focused on StreptInCor, a candidate vaccine that contains 55 synthetic amino acid residues of the C-terminal region of the $M$ protein. The formulation of StreptInCor with aluminum hydroxide (alum) was tested in inbred, outbred, and transgenic mice harboring human HLA class II alleles. High titers of specific antibodies and no cross-reactions with cardiac proteins or deleterious effects in vaccinated animals were observed (23-25).

The aim of the present toxicology work was to verify whether the candidate vaccine triggers toxic effects and identify target organs and deleterious effects on animal physiology and hematological, biochemical, anatomical, and histopathological parameters.

\section{MATERIALS AND METHODS}

Repeated intramuscular (IM) dose toxicity tests under conditions of good laboratory practice (GLP) and following national (26) and international standards were conducted by TECAM
- Tecnologia Ambiental (São Roque, SP, Brazil), and they were identified as 5517/2015IM, protocol 27 (27, 28). All procedures were in accordance with national guidelines of the National Animal Experiment Placebo Council (CONCEA) and Committee for Animal Care and Use (COBEA) and international requirements based on the "Guide for the Care and Use of Laboratory Animals" (29).

The Wistar rats were kept in a facility accredited by the Association for Assessment and Accreditation of Laboratory Animal Care (AAALAC) and Credenciamento Institucional para Atividades com Animais em Ensino ou Pesquisa (CIAEP)/CONCEA under number 01.0242.214.

The experimental design of the rat IM toxicity tests is shown in Figures 1, 2.

\section{StreptInCor Candidate Vaccine}

PolyPeptide Laboratories Inc. (Torrance, CA, USA) manufactured the synthetic peptide StreptInCor based on good manufacturing practice (GMP) standards. The vaccine formulation was prepared at Butantan Institute (São Paulo, Brazil). StreptInCor in different doses are emulsified in aluminum hydroxide as adjuvant, as follows: lot $15055(50 \mu \mathrm{g} / \mathrm{ml}$, low dose); lot $15056(100 \mu \mathrm{g} / \mathrm{ml}$, medium dose); lot 15057 $(200 \mu \mathrm{g} / \mathrm{ml}$, high dose); and lot 15054 (placebo formulation).

\section{Animals}

Outbred male and female Wistar rats (Rattus norvegicus) aged 7-9 weeks were bred at TECAM - Tecnologia Ambiental.

Both acute IM toxicity tests and repeated IM dose toxicity tests were evaluated. Only rats deemed healthy after evaluation by a veterinarian and without any clinical manifestation were selected for the study. The animals were acclimated 5 days before the studies and kept in monitored rooms at average temperature and humidity conditions of $20.8^{\circ} \mathrm{C}$ and $71.2 \%$, respectively. The rats received species-specific rations (Nuvilab CR-1, Quimtia S.A., Colombo, PR, Brazil) and filtered water ad libitum. They were maintained in a 12 -h light/dark cycle with $\sim 10-12$ air changes per hour.

\section{Administration of the StreptInCor Candidate Vaccine}

The candidate vaccine was formulated at the concentrations of 50,100 , and $200 \mu \mathrm{g} / \mathrm{ml}$ of StreptInCor, plus alum $(0.5 \mathrm{mg} / \mathrm{ml}$ of aluminum hydroxide), thimerosal $(0.004 \mathrm{mg} / \mathrm{ml})$, and phosphate buffered saline solution.

Previously identified animals received one IM injection of 250 $\mu l$ of StreptInCor or placebo solution on the thigh muscles of their hind limbs, which had been trichotomized.

The toxicity due to acute immune response was evaluated in Experimental Group I, which included 50 Wistar rats $(25$ males and 25 females). On day 0 , the rats received only one IM injection of $250 \mu \mathrm{l}$ of StreptInCor with different concentrations, as follows: $50 \mu \mathrm{g} / \mathrm{ml}$ (low dose) (five males and five females); $100 \mu \mathrm{g} / \mathrm{ml}$ (medium dose) (five males and five females); and $200 \mu \mathrm{g} / \mathrm{ml}$ (high dose) (10 males and 10 females). Animals of placebo subgroup (five males and five females) received only one IM injection of $250 \mu \mathrm{l}$ of a saline plus aluminum hydroxide solution, on day 0 . 


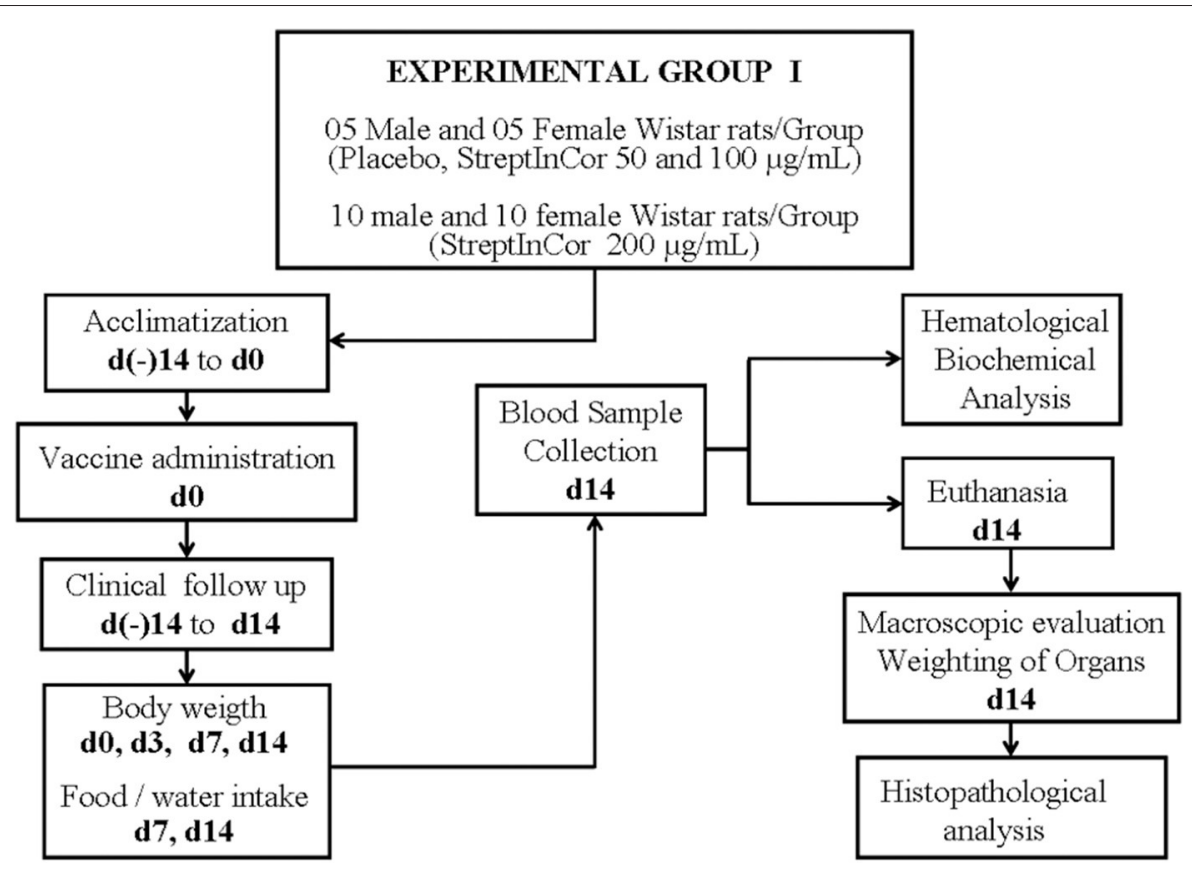

FIGURE 1 | Experimental design.

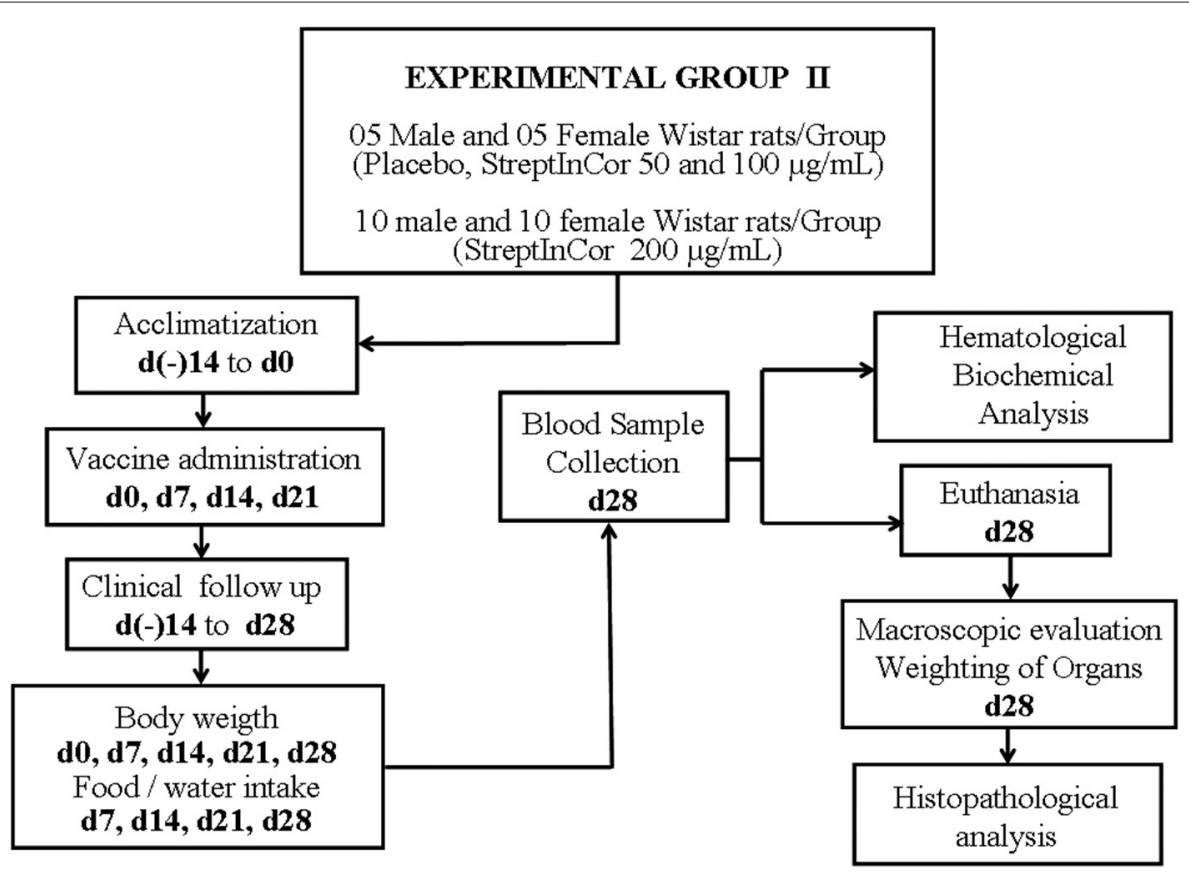

FIGURE 2 | Experimental design.

The toxicity effect of StreptInCor repeated doses was evaluated in Experimental Group II, which included 50 Wistar rats (25 males and 25 females). On days $0,7,14$, and 21 , the animals received one IM injection of $250 \mu \mathrm{l}$ of StreptInCor with different concentrations, as follows: $50 \mu \mathrm{g} / \mathrm{ml}$ (low dose) (five males and five females); $100 \mu \mathrm{g} / \mathrm{ml}$ (medium dose) (five males and five females); and $200 \mu \mathrm{g} / \mathrm{ml}$ (high dose) (10 males and 10 females). Rats of placebo subgroup (five males and five females) received one IM injection of $250 \mu \mathrm{l}$ of a saline plus aluminum hydroxide solution, on days $0,7,14$, and 21 . 
A recovery group of rats underwent the same protocol of the Experimental Group II protocol and recovered for 2 weeks before euthanasia on day 42. They underwent two additional measurements for body weight and food consumption, on days 35 and 42 .

\section{Clinical Follow-Up}

The animals were individually monitored throughout the acclimation as well as during the experimental period. Experienced veterinarians classified the severity of clinical signs as mild, moderate, or severe based on physical examination. Clinical observations included changes in the fur, skin, eyes, and mucous membranes; occurrence of secretions and excretions; and autonomic activity (lacrimation, piloerection, changes in the pupils, and respiratory pattern). The veterinarians were also vigilant for possible changes in gait, posture, and reaction to manipulation as well as the presence of tonic or clonic movements and stereotypies, such as excessive grooming, repetitive circulatory movements, self-mutilation, and walking backwards. Finally, local tolerance was assessed by the presence of edema, erythema, desquamation, wounding, alopecia, and any other signs of local irritation and/or inflammation.

The body weights of the animals were measured on days 0 , 3, 7, and 14 for Group I and on days $0,7,14,21$, and 28 for Group II. Food consumption was measured on days 7 and 14 for Group I and on days 7, 14, 21, and 28 for Group II. The recovery group had two additional measurements for body weights and food consumption (days 35 and 42).

\section{Euthanasia}

All animals were sedated by an IM injection of a combination of xylazine $(8 \mathrm{mg} / \mathrm{kg})$ and ketamine $(65 \mathrm{mg} / \mathrm{kg})$. Blood samples were collected for hematological and biochemical analyses through cardiac puncture after deep anesthesia and prior to euthanasia.

TABLE 1 | Hematology data from Wistar rats vaccinated with StreptlnCor at different doses (50, 100 or $200 \mu \mathrm{g} / \mathrm{mL}) \mathrm{compared} \mathrm{with} \mathrm{placebo.}$

\begin{tabular}{|c|c|c|c|c|}
\hline Males & Placebo & $50 \mu \mathrm{g} / \mathrm{mL}$ & $100 \mu \mathrm{g} / \mathrm{mL}$ & $200 \mu \mathrm{g} / \mathrm{mL}$ \\
\hline $\operatorname{RBC}\left(10^{12} / \mathrm{L}\right)$ & $9.36 \pm 0.14$ & $7.78 \pm 0.13^{*}$ & $8.34 \pm 0.12$ & $8.26 \pm 0.20$ \\
\hline Hemoglobin (g/L) & $172.60 \pm 6.33$ & $145.80 \pm 2.52$ & $150.60 \pm 2.77$ & $154.50 \pm 4.33$ \\
\hline Hematocrit (fraction) & $0.52 \pm 0.02$ & $0.44 \pm 0.01$ & $0.46 \pm 0.01$ & $0.45 \pm 0.01$ \\
\hline MCV (fL) & $55.29 \pm 1.51$ & $56.40 \pm 1.02$ & $54.92 \pm 1.06$ & $54.89 \pm 0.73$ \\
\hline $\mathrm{MCH}(\mathrm{pg})$ & $18.43 \pm 0.50$ & $18.76 \pm 0.28$ & $18.07 \pm 0.45$ & $18.70 \pm 0.18$ \\
\hline $\mathrm{MCHC}(\mathrm{g} / \mathrm{L})$ & $333.30 \pm 0.21$ & $332.70 \pm 2.04$ & $329.00 \pm 2.23$ & $340.80 \pm 2.33$ \\
\hline Platelets $\left(10^{9} / \mathrm{L}\right)$ & $910.80 \pm 116.40$ & $913.50 \pm 51.40$ & $856.20 \pm 85.00$ & $773.90 \pm 123.00$ \\
\hline Leukocytes (109/L) & $6.03 \pm 0.75$ & $5.50 \pm 0.35$ & $7.46 \pm 0.76$ & $5.36 \pm 0.42$ \\
\hline Lymphocytes $\left(10^{9} / \mathrm{L}\right)$ & $4.97 \pm 0.63$ & $4.52 \pm 0.32$ & $6.14 \pm 0.67$ & $4.26 \pm 0.33$ \\
\hline Monocytes $\left(10^{9} / \mathrm{L}\right)$ & $0.13 \pm 0.01$ & $0.12 \pm 0.01$ & $0.13 \pm 0.01$ & $0.10 \pm 0.01$ \\
\hline Granulocytes $\left(10^{9} / \mathrm{L}\right)$ & $0.94 \pm 0.16$ & $0.86 \pm 0.05$ & $1.19 \pm 0.15$ & $1.01 \pm 0.11$ \\
\hline Lymphocytes (fraction) & $0.82 \pm 0.02$ & $0.82 \pm 0.01$ & $0.82 \pm 0.02$ & $0.80 \pm 0.02$ \\
\hline Monocytes (fraction) & $0.02 \pm 0.00$ & $0.02 \pm 0.00$ & $0.02 \pm 0.00$ & $0.02 \pm 0.00$ \\
\hline Granulocytes (fraction) & $0.15 \pm 0.02$ & $0.16 \pm 0.01$ & $0.16 \pm 0.02$ & $0.19 \pm 0.02$ \\
\hline Females & Placebo & $50 \mu \mathrm{g} / \mathrm{mL}$ & $100 \mu \mathrm{g} / \mathrm{mL}$ & $200 \mu \mathrm{g} / \mathrm{mL}$ \\
\hline $\operatorname{RBC}\left(10^{12} / \mathrm{L}\right)$ & $7.65 \pm 0.01$ & $7.77 \pm 0.26$ & $7.53 \pm 0.19$ & $7.78 \pm 0.19$ \\
\hline Hemoglobin (g/L) & $141.20 \pm 1.24$ & $142.00 \pm 3.05$ & $136.60 \pm 2.98$ & $144.00 \pm 2.70$ \\
\hline Hematocrit (fraction) & $0.42 \pm 0.01$ & $0.43 \pm 0.01$ & $0.41 \pm 0.01$ & $0.43 \pm 0.01$ \\
\hline MCV (fL) & $54.54 \pm 0.18$ & $55.24 \pm 0.72$ & $54.99 \pm 0.38$ & $55.10 \pm 0.58$ \\
\hline $\mathrm{MCH}(\mathrm{pg})$ & $18.46 \pm 0.13$ & $18.29 \pm 0.27$ & $18.15 \pm 0.11$ & $18.54 \pm 0,21$ \\
\hline $\mathrm{MCHC}(\mathrm{g} / \mathrm{L})$ & $338.50 \pm 1.88$ & $331.20 \pm 1.27$ & $330.10 \pm 1.65$ & $336.60 \pm 1.78$ \\
\hline Platelets $\left(10^{9} / \mathrm{L}\right)$ & $802.00 \pm 48.14$ & $947.40 \pm 93.40$ & $769.60 \pm 52.30$ & $800.80 \pm 112.20$ \\
\hline Leukocytes $\left(10^{9} / \mathrm{L}\right)$ & $4.08 \pm 0.37$ & $7.40 \pm 0.47^{\star}$ & $2.44 \pm 0.38$ & $4.15 \pm 0.30$ \\
\hline Lymphocytes (109/L) & $3.16 \pm 0.30$ & $6.00 \pm 0.40^{*}$ & $1.78 \pm 0.34$ & $3.41 \pm 0.29$ \\
\hline Monocytes $\left(10^{9} / \mathrm{L}\right)$ & $0.09 \pm 0.01$ & $0.13 \pm 0.01$ & $0.06 \pm 0.00$ & $0.06 \pm 0.00$ \\
\hline Granulocytes (109/L) & $0.84 \pm 0.17$ & $1.26 \pm 0.07$ & $0.60 \pm 0.06$ & $0.68 \pm 0.03$ \\
\hline Lymphocytes (fraction) & $0.77 \pm 0.03$ & $0.81 \pm 0.05$ & $0.71 \pm 0.05$ & $0.81 \pm 0.01$ \\
\hline Monocytes (fraction) & $0.02 \pm 0.00$ & $0.02 \pm 0.00$ & $0.024 \pm 0.00$ & $0.02 \pm 0.00$ \\
\hline Granulocytes (fraction) & $0.21 \pm 0.03$ & $0.17 \pm 0.00$ & $0.27 \pm 0.05$ & $0.17 \pm 0.01$ \\
\hline
\end{tabular}

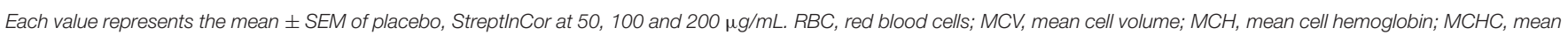

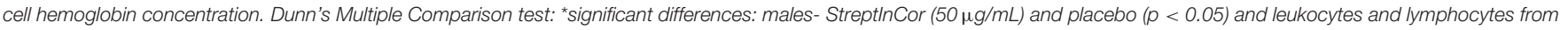
females treated with StreptInCor $(50 \mu \mathrm{g} / \mathrm{mL})$ and placebo $(p<0.05)$. 
The veterinarians euthanized the rats by exsanguination after confirmation of deep anesthesia. After 2 weeks (day 14) and 4 weeks (day 28), rats from Groups I and II were euthanized, respectively. Rats from recovery group were euthanized after 6 weeks, on day 42 .

\section{Hematological and Biochemical Analyses}

Hematological tests, including the red blood cell count, hemoglobin concentration, hematocrit, mean corpuscular volume $(\mathrm{MCV})$, mean corpuscular hemoglobin $(\mathrm{MCH}), \mathrm{MCH}$ concentration $(\mathrm{MCHC})$, white blood cell count, and platelet count were evaluated using HEMATOClin 2.8 Vet (QUIBASA Bioclin, Brazil).

Commercial kits for biochemical parameters were used to determine the serum levels of glucose, total cholesterol, urea, creatinine, alanine aminotransferase, aspartate aminotransferase, albumin, globulin, total protein, sodium, chloride, and potassium. The results were obtained by spectrometry in liquid medium by using the semiautomatic TP Analyzer (Thermo-Plate, Brazil).

\section{Necropsy, Wet Organ Weight, and Histopathological Analysis}

Necropsies of all the animals were performed by veterinarians who collected tissue samples for histological analysis. Organs such as the brain, liver, kidneys, adrenal glands, heart, gonads (testis and epididymis or ovary), thymus, and spleen were collected; and their relative organ weight (weight of organ as a percentage of the total body weight of each rat) was calculated and compared with the relative organ weight of the placebo group rats. After macroscopic evaluation, tissue samples of the brain, lung, stomach, esophagus, small intestine, large intestine, liver, pancreas, kidney, adrenal glands, heart, gonad (testis or ovary), urinary bladder, femur, thymus, spleen, and lymph nodes were fixed in $10 \%$ buffered formalin. Fixed samples were dehydrated in alcohol baths in a concentration gradient, cleared in xylene, and embedded in paraffin blocks. Five micro sections were cut and mounted on slides and stained by the hematoxylin and eosin method.

\section{Statistical Analysis}

For each parameter analyzed, the data are expressed as the mean \pm the standard error of the mean (SEM) between the different animals of each group. All data were examined by the D'Agostino and Pearson omnibus normality tests to verify whether the data could be analyzed by parametric tests. When the data passed the normality test, we employed a one-way analysis of variance and Tukey's post-test to compare all pairs of columns. If the data did not pass the normality test, we used the Kruskal-Wallis test and Dunn's post-test to compare all pairs of columns. We used GraphPad Prism software version 5.01 for Windows (GraphPad Software, San Diego California USA, www.graphpad.com) to analyze the data, and $p$-values $<0.05$ were considered significant.

\section{RESULTS}

Clinical signs of toxicity or intolerance at the site of administration and mortality were not observed during the

TABLE 2 | Biochemistry data from Wistar rats vaccinated with repeated injections of StreptlnCor at 50, 100 or $200 \mu \mathrm{g} / \mathrm{mL}$ doses compared with placebo.

\begin{tabular}{|c|c|c|c|c|}
\hline Males & Placebo & $50 \mu \mathrm{g} / \mathrm{mL}$ & $100 \mu \mathrm{g} / \mathrm{mL}$ & $200 \mu \mathrm{g} / \mathrm{mL}$ \\
\hline Urea (mmol/L) & $16.94 \pm 1.91$ & $15.60 \pm 0.46$ & $21.49 \pm 1.15$ & $16.26 \pm 0.86$ \\
\hline Creatinine ( $\mu \mathrm{mol} / \mathrm{L})$ & $42.43 \pm 3.92$ & $29.88 \pm 8.64$ & $57.11 \pm 16.32$ & $37.66 \pm 3.18$ \\
\hline AST (IU/L) & $125.20 \pm 15.18$ & $78.40 \pm 18.79$ & $115.90 \pm 12.64$ & $115.40 \pm 14.50$ \\
\hline ALT (IU/L) & $30.46 \pm 8.72$ & $27.94 \pm 5.48$ & $34.78 \pm 1.72$ & $32.39 \pm 2.67$ \\
\hline Glucose (mmol/L) & $9.94 \pm 1.63$ & $12.57 \pm 0.77$ & $12.39 \pm 1.34$ & $12.43 \pm 0.57$ \\
\hline Cholesterol (mmol/L) & $2.24 \pm 0.42$ & $1.85 \pm 0.11$ & $1.78 \pm 0.05$ & $1.75 \pm 0.10$ \\
\hline Albumin (g/L) & $31.30 \pm 0.86$ & $34.46 \pm 1.59$ & $29.76 \pm 1.11$ & $29.09 \pm 0.57$ \\
\hline Globulin (g/L) & $38.06 \pm 3.81$ & $41.08 \pm 4.18$ & $43.22 \pm 5.39$ & $35.66 \pm 1.46$ \\
\hline Total Protein (g/L) & $69.36 \pm 4.67$ & $75.54 \pm 5.58$ & $72.98 \pm 6.48$ & $64.75 \pm 1.97$ \\
\hline Females & Placebo & $50 \mu \mathrm{g} / \mathrm{mL}$ & $100 \mu \mathrm{g} / \mathrm{mL}$ & $200 \mu \mathrm{g} / \mathrm{mL}$ \\
\hline Urea (mmol/L) & $21.32 \pm 1.40$ & $16.72 \pm 1.15$ & $13.94 \pm 1.51$ & $15.79 \pm 1.08$ \\
\hline Creatinine ( $\mu \mathrm{mol} / \mathrm{L})$ & $47.38 \pm 8.03$ & $56.22 \pm 2.45$ & $56.40 \pm 5.67$ & $55.13 \pm 3,0$ \\
\hline AST (IU/L) & $125.60 \pm 16.28$ & $125 \pm 60,25.53$ & $109.20 \pm 6.15$ & $81.28 \pm 5.04$ \\
\hline ALT (IU/L) & $26.00 \pm 4.91$ & $31.52 \pm 3.32$ & $23.76 \pm 4.96$ & $30.71 \pm 1.45$ \\
\hline Glucose (mmol/L) & $9.41 \pm 0.55$ & $10.73 \pm 1.09$ & $10.07 \pm 0.67$ & $11.19 \pm 0.58$ \\
\hline Cholesterol (mmol/L) & $1.68 \pm 0.09$ & $1.74 \pm 0.13$ & $1.38 \pm 0.15$ & $1.83 \pm 0.10$ \\
\hline Albumin (g/L) & $33.20 \pm 1.32$ & $40.44 \pm 8.62$ & $31.30 \pm 0.91$ & $33.27 \pm 0.82$ \\
\hline Globulin (g/L) & $33.92 \pm 2.62$ & $30.46 \pm 1.86$ & $30.94 \pm 1.37$ & $32.27 \pm 0.82$ \\
\hline Total Protein (g/L) & $67.12 \pm 3.88$ & $70.90 \pm 8.68$ & $62.24 \pm 2.07$ & $65.54 \pm 1.47$ \\
\hline
\end{tabular}

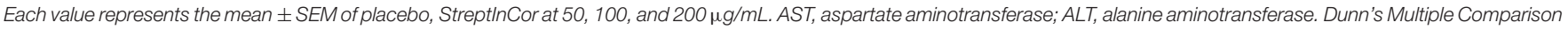
test, no statistically significant differences were observed. 
TABLE 3 | Relative organ weights from the male and female Wistar rats after administration of StreptlnCor at 50, $100,200 \mu \mathrm{g} / \mathrm{mL}$ doses or placebo.

\begin{tabular}{|c|c|c|c|c|}
\hline Males & Placebo & $50 \mu \mathrm{g} / \mathrm{mL}$ & $100 \mu \mathrm{g} / \mathrm{mL}$ & $200 \mu \mathrm{g} / \mathrm{mL}$ \\
\hline Heart & $0.33 \pm 0.02$ & $0.30 \pm 0.01$ & $0.30 \pm 0.01$ & $0.31 \pm 0.02$ \\
\hline Liver & $3.36 \pm 0.40$ & $3.70 \pm 0.14$ & $3.85 \pm 0.15$ & $3.75 \pm 0.93$ \\
\hline Kidney & $0.71 \pm 0.05$ & $0.67 \pm 0.03$ & $0.69 \pm 0.03$ & $0.71 \pm 0.02$ \\
\hline Adrenal & $0.01 \pm 0.00$ & $0.02 \pm 0.00$ & $0.02 \pm 0.00$ & $0.02 \pm 0.00$ \\
\hline CNS & $0.64 \pm 0.07$ & $0.57 \pm 0.02$ & $0.58 \pm 0.01$ & $0.58 \pm 0.03$ \\
\hline Spleen & $0.20 \pm 0.02$ & $0.24 \pm 0.01$ & $0.20 \pm 0.01$ & $0.21 \pm 0.01$ \\
\hline Thymus & $0.16 \pm 0.01$ & $0.20 \pm 0.02$ & $0.18 \pm 0.01$ & $0.16 \pm 0.01$ \\
\hline Epydidimis+Testicle & $1.24 \pm 0.08$ & $1.57 \pm 0.22$ & $1.60 \pm 0.15$ & $1.58 \pm 0.09$ \\
\hline Females & Placebo & $50 \mu \mathrm{g} / \mathrm{mL}$ & $100 \mu \mathrm{g} / \mathrm{mL}$ & $200 \mu \mathrm{g} / \mathrm{mL}$ \\
\hline Heart & $0.32 \pm 0.01$ & $0.35 \pm 0.03$ & $0.33 \pm 0.01$ & $0.32 \pm 0.01$ \\
\hline Liver & $3.64 \pm 0.16$ & $3.82 \pm 0.13$ & $3.48 \pm 0.13$ & $3.47 \pm 0.13$ \\
\hline Kidney & $0.76 \pm 0.01$ & $0.75 \pm 0.02$ & $0.76 \pm 0.04$ & $0.78 \pm 0.02$ \\
\hline Adrenal & $0.03 \pm 0.01$ & $0.03 \pm 0.01$ & $0.048 \pm 0.01$ & $0.36 \pm 0.00$ \\
\hline CNS & $0.85 \pm 0.02$ & $0.79 \pm 0.03$ & $0.86 \pm 0.13$ & $0.84 \pm 0.02$ \\
\hline Spleen & $0.23 \pm 0.01$ & $0.23 \pm 0.01$ & $0.23 \pm 0.01$ & $0.25 \pm 0.01$ \\
\hline Thymus & $0.19 \pm 0.03$ & $0.22 \pm 0.02$ & $0.24 \pm 0.00$ & $0.21 \pm 0.01$ \\
\hline Ovary & $0.08 \pm 0.01$ & $0.07 \pm 0.01$ & $0.10 \pm 0.03$ & $0.07 \pm 0.01$ \\
\hline
\end{tabular}

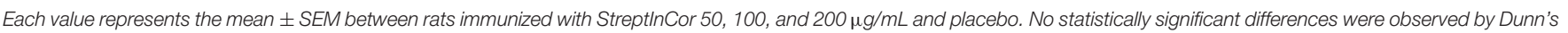
Multiple Comparison test.

acute toxicity study. In addition, the animals used in this experiment showed body weight gains from 220 to $300 \mathrm{~g}$ during acute phase (Group I) and 180 to $250 \mathrm{~g}$ during chronic phase (Group II) consistent with the observed food intake.

Animals from all groups displayed chronic granulomatous inflammation in skeletal muscle at the site of injection: $66.7 \%$ of the animals in the placebo (two males and two females); and $66.7 \%$ (two males and two females), 16.7\% (one female), and $50.0 \%$ (two males and one female) of the animals treated with 50, 100, and $200 \mu \mathrm{g}$ of StreptInCor, respectively. Considering that animals from all groups studied in the acute toxicity test showed good tolerance to StreptInCor, we maintained the same concentrations to evaluate the repeated dose toxicity.

\section{Clinical Follow-Up}

No mortality or clinical signs related to the injection of StreptInCor at 50, 100, or $200 \mu \mathrm{g} / \mathrm{ml}$ were recorded. Food intake and water intake were similar between the placebo and experimental groups. In addition, the weight gains were similar among animals of all groups, being around $220 \mathrm{~g}$ in placebo and $150 \mathrm{~g}$ in immunized animals.

\section{Hematological and Biochemical Analyses}

The repeated injections at different doses of the candidate vaccine did not interfere markedly with the hematology data; however, we observed that erythrocytes from the male rats that received $50 \mu \mathrm{g} / \mathrm{ml}$ differed from those obtained in the placebo group $(p$ $<0.05)$. On the other hand, females vaccinated with $50 \mu \mathrm{g} / \mathrm{ml}$ presented an increased leukocyte count $(p<0.05)$ than the placebo group due to an increased number of lymphocytes $(p<$ 0.05) (Table 1).
Metabolic alterations due to the injection of placebo or the different doses of StreptInCor candidate vaccine were not observed (Table 2).

\section{Necropsy, Wet Organ Weight, and Histopathological Analysis}

No macroscopic alterations were observed. The organ wet weights as well as the relative weights were similar among the experimental groups and placebo animals (Table 3 ).

The main histological finding observed in all experimental groups was chronic granulomatous inflammation in the skeletal muscle at the site of injection in both the placebo and immunized animals, as follows: $70 \%$ of rats in the placebo group (four males and three females); and 70\% (four males and three females), $40 \%$ (one male and three females), and 65\% (six males and seven females) of animals that received 50, 100, and $200 \mu \mathrm{g}$ of StreptInCor, respectively.

Histological analysis of the other tissues did not show alterations compared with that of placebo animals, and this response was dependent of the StreptInCor dose (Figures 3, 4).

\section{DISCUSSION}

The present work is part of a set of experiments performed to develop an effective and safe GAS vaccine capable of inducing protection against oropharyngeal infections, RF/RHD, necrotizing fasciitis, and toxic shock syndrome. Streptococcus pyogenes is a strictly human pathogen and normally does not induce disease in animals. This fact causes some difficulties to 


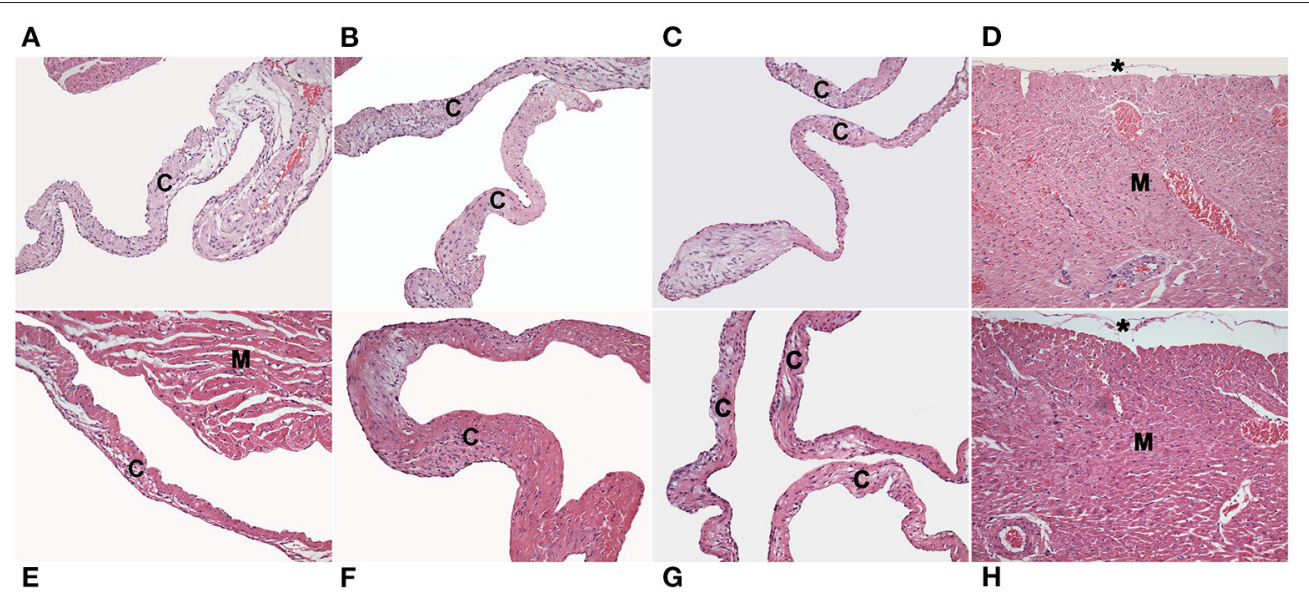

FIGURE 3 | Photomicrographs of histological sections of the tricuspid (A), mitral (B) and aortic (C) valves, and myocardium (D) from Wistar rats injected with placebo. The tricuspid (E), mitral (F) and aortic (G) valves, and myocardium (H) from rats injected with a high dose of StreptlnCor (200 $\mu \mathrm{g} / \mathrm{ml})$. There is no necrosis, inflammatory infiltrate, neovascularization, or fibrosis in the valve cusps (c), myocardium (M), or epicardium (*). Hematoxylin and eosin staining, $\times 200$.

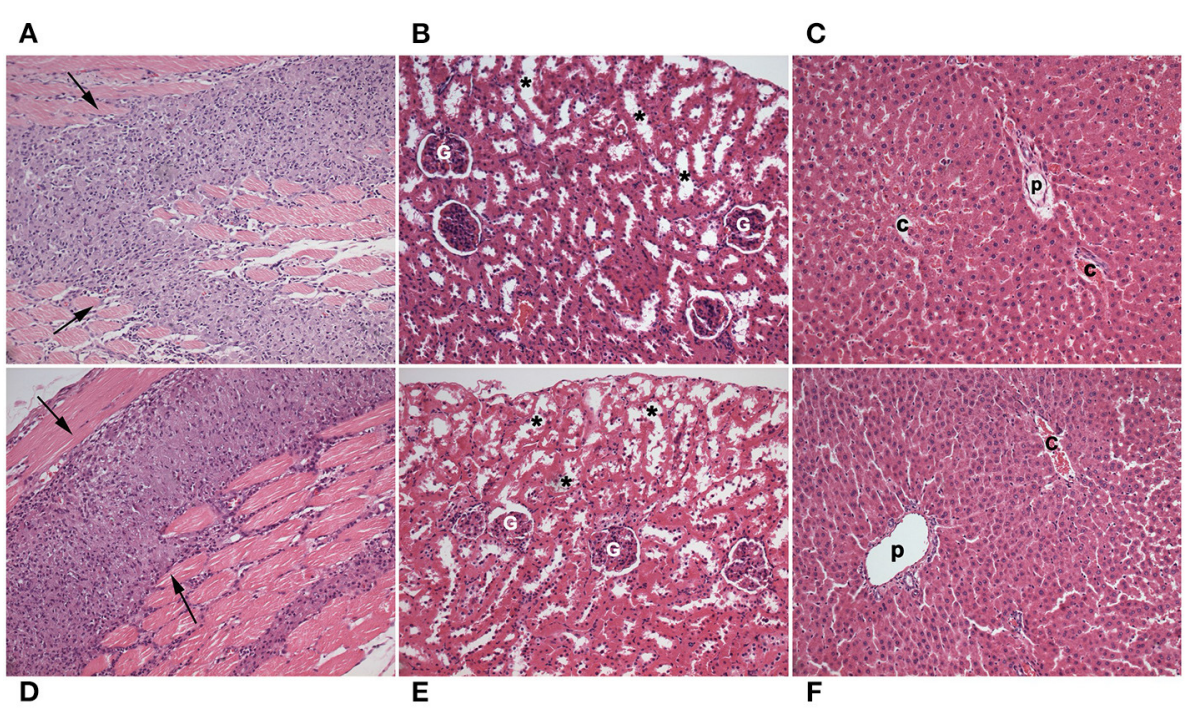

FIGURE 4 | Photomicrographs of histological sections of skeletal muscle (A), kidney (B), and liver (C) from Wistar rats injected with placebo, and of skeletal muscle (D), kidney (E), and liver (F) from rats injected with high dose of StreptlnCor ( $200 \mu \mathrm{g} / \mathrm{mL}$ ). Chronic granulomatous inflammation (arrows) in skeletal muscle at the site of placebo (A) and StreplnCor (D) injections. There are not necrosis, inflammatory infiltrate, neovascularization, or fibrosis in renal or hepatic tissues. Hematoxylin and eosin staining, ×200. (G) Glomerulus; (*) proximal tubules; (p) portal tract; (c) centrilobular hepatic vein.

develop an ideal animal model. Despite of it, encouraging results from studies with mice (Swiss, Balb-c, and HLA class II Tg mice) (23-25) and minipigs (30) showed that StreptInCor candidate vaccine is safe.

In this study, we conducted non-clinical safety tests to determine whether StreptInCor candidate vaccine could induce adverse reactions in other animal species.

Because no adverse effects or mortality were observed at any of the concentrations of StreptInCor $(50,100$, and $200 \mu \mathrm{g} / \mathrm{ml})$ in the acute toxicity study (single dose, 14 days), the same formulations were tested in the repeated dose toxicity studies in two species, non-rodents (30) and rodents (Wistar rats), as described here.

No mortality or major changes related to feeding, hydration, or weight gain were observed among the animals. The most important difference in relation to the placebo group was the increased number of leukocytes (lymphocytes, monocytes, and granulocytes) in the females that received $50 \mu \mathrm{g}$ of StreptInCor.

Repeated immunizations at intervals of 7 days are indicated for evaluation of toxicity effects. Of note, this protocol is not adequate for the evaluation of humoral response $(31,32)$. 
Macroscopic analysis of tissues and organs showed no toxicological effects of the administration of StreptInCor in Wistar rats. The microscopic examination showed the presence of chronic granulomatous inflammation at the site of the StreptInCor and placebo injections (skeletal muscle) due to the presence of the adjuvant (aluminum hydroxide) in the formulations (33).

Adjuvants are important for enhancing the specific immune response against antigens in vaccines. Aluminum hydroxide induces the migration of neutrophils and eosinophils as well as dendritic cells and monocytes/macrophages to the site of inoculation $(34,35)$. Eosinophils are able to secrete preformed IL-4 and may play an immunomodulatory role in the activation of $\mathrm{B}$ cells elicited by aluminum hydroxide (36). Dendritic cells and macrophages function as inducers of adaptive immunity by presenting antigens to $\mathrm{T}$ cells $(33,37)$.

A major concern with the development of an M protein-based GAS vaccine is the possibility of inducing an autoimmune response, such as RF/RHD. Antibodies raised against the $\mathrm{N}$-terminal region have been linked to RF/RHD pathogenesis $(4,18,38)$. The C-terminal region that is conserved did not induce cross-reactive antibodies. In this context, in previous studies on isogenic, outbred, and HLA class IItransgenic mice immunized with StreptInCor $(24,25)$, no heart-tissue cross-reactive antibodies or deleterious reactions in the heart (myocardium and valves) or other tissues were observed. The repeated dose toxicity test performed on Wistar rats presented here showed no signs of toxic reaction in the heart or any of the organs evaluated after the administration of the StreptInCor candidate vaccine.

\section{REFERENCES}

1. Watkins DA, Johnson CO, Colquhoun SM, Karthikeyan G, Beaton A, Bukhman G, et al. Global, regional, and national burden of rheumatic heart disease, 1990-2015. N Engl J Med. (2017) 377:713-22. doi: 10.1056/NEJMoa1603693

2. Bowen AC, Mahé A, Hay RJ, Andrews RM, Steer AC, Tong SYC, et al. The global epidemiology of impetigo: a systematic review of the population prevalence of impetigo and pyoderma. PLoS ONE. (2015) 10:e0136789. doi: 10.1371/journal.pone.0136789

3. Shaikh N, Leonard E, Martin JM. Prevalence of streptococcal pharyngitis and streptococcal carriage in children: a meta-analysis. Pediatrics. (2010) 126:E557-64. doi: 10.1542/peds.2009-2648

4. Karthikeyan G, Guilherme L. Acute rheumatic fever (vol 392, pg 161, 2018). Lancet. (2018) 392:820. doi: 10.1016/S0140-6736(18)30999-1

5. Sampaio RO, Fae KC, Demarchi LMF, Pomerantzeff PMA, Aiello VD, Spina GS, et al. Rheumatic heart disease: 15 years of clinical and immunological follow-up. Vasc Health Risk Manage. (2007) 3:1007-17.

6. Martin WJ, Steer AC, Smeesters PR, Keeble J, Inouye M, Carapetis J, et al. Post-infectious group A streptococcal autoimmune syndromes and the heart. Autoimmun Rev. (2015) 14:710-25. doi: 10.1016/j.autrev.2015.04.005

7. Carapetis JR, Beaton A, Cunningham MW, Guilherme L, Karthikeyan C, Mayosi BM, et al. Acute rheumatic fever and rheumatic heart disease. Nat Rev Dis Prim. (2016) 2:15084. doi: 10.1038/nrdp.2015.84

\section{CONCLUSIONS}

The results of repeated StreptInCor candidate injection in doses ranging from 50 to $200 \mu \mathrm{g} / \mathrm{ml}$ on Wistar rats presented here indicate that the StreptInCor candidate vaccine is non-toxic and well-tolerated in rodent animal models.

\section{DATA AVAILABILITY STATEMENT}

The raw data supporting the conclusions of this article will be made available by the authors, without undue reservation.

\section{ETHICS STATEMENT}

The animal study was reviewed and approved by National Animal Experiment Control Council (CONCEA) and Committee for Animal Care and Use (COBEA) and international requirements based on the Guide for the Care and Use of Laboratory Animals.

\section{AUTHOR CONTRIBUTIONS}

LS-R, EP, and RA: performed animal experimentation and analysis of data. RS: contributed with manuscript preparation and analysis of results. LD: histopathology analysis and manuscript preparation. JK: director of Immunology lab. LG: analysis of the data and manuscript preparation. All authors contributed to the article and approved the submitted version.

\section{FUNDING}

This work was supported by grants from Banco Nacional de Desenvolvimento (BNDES), No. 14.2.1159.1, 2015-2020, Brazil.

8. Guilherme L, de Barros SF, Kohler KF, Santos SR, Ferreira FM, Silva WR, et al. Rheumatic heart disease: pathogenesis and vaccine. Curr Protein Peptide Sci. (2018) 19:900-8. doi: 10.2174/13892037186661707251 15855

9. Guilherme L, Weidebach W, Kiss MH, Snitcowsky R, Kalil J. Association of human-leukocyte class-II antigens with rheumatic-fever or rheumatic heart-disease in a brazilian population. Circulation. (1991) 83:19958. doi: 10.1161/01.CIR.83.6.1995

10. Galvin JE, Hemric ME, Ward K, Cunningham MW. Cytotoxic mAb from rheumatic carditis recognizes heart valves and laminin. J Clin Investig. (2000) 106:217-24. doi: 10.1172/JCI7132

11. Ellis NMJ, Li Y, Hildebrand W, Fischetti VA, Cunningham MW. $T$ cell mimicry and epitope specificity of cross-reactive $\mathrm{T}$ cell clones from rheumatic heart disease. J Immunol. (2005) 175:5448-56. doi: 10.4049/jimmunol.175.8.5448

12. Guilherme L, Fae KC, Higa F, Chaves L, Oshiro SE, De Barros SF, et al. Towards a vaccine against rheumatic fever. Clin Dev Immunol. (2006) 13:12532. doi: 10.1080/17402520600877026

13. Cunningham MW. Rheumatic fever, autoimmunity, and molecular mimicry: the streptococcal connection. Int Rev Immunol. (2014) 33:314-29. doi: 10.3109/08830185.2014.917411

14. Bessen D, Jones KF, Fischetti VA. Evidence for 2 distinct classes of streptococcal m-protein and their relationship to rheumatic-fever. J Exp Med. (1989) 169:269-83. doi: 10.1084/jem.169.1.269 
15. Smeesters PR, McMillan DJ, Sriprakash KS. The streptococcal M protein: a highly versatile molecule. Trends Microbiol. (2010) 18:275-82. doi: 10.1016/j.tim.2010.02.007

16. McMillan DJ, Dreze PA, Vu T, Bessen DE, Guglielmini J, Steer AC, et al. Updated model of group A Streptococcus $M$ proteins based on a comprehensive worldwide study. Clin Microbiol Infect. (2013) 19:E2229. doi: 10.1111/1469-0691.12134

17. Lancefield RC. Current knowledge of type-specific $M$ antigens of group A streptococci. J Immunol. (1962) 89:307.

18. Cunningham MW. Pathogenesis of group A streptococcal infections. Clin Microbiol Rev. (2000) 13:470-511. doi: 10.1128/CMR.13.3.470

19. Bisno AL, Rubin FA, Cleary PP, Dale JB. Prospects for a group a streptococcal vaccine: rationale, feasibility, and obstacles - report of a national institute of allergy and infectious diseases workshop. Clin Infect Dis. (2005) 41:11506. doi: 10.1086/444505

20. McNeil SA, Halperin SA, Langley JM, Smith B, Warren A, Sharratt GP, et al. Safety and immunogenicity of 26-valent group A Streptococcus vaccine in healthy adult volunteers. Clin Infect Dis. (2005) 41:111422. doi: $10.1086 / 444458$

21. Steer AC, Carapetis JR, Dale JB, Fraser JD, Good MF, Guilherme L, et al. Status of research and development of vaccines for Streptococcus pyogenes. Vaccine. (2016) 34:2953-8. doi: 10.1016/j.vaccine.2016. 03.073

22. Sekuloski S, Batzloff MR, Griffin P, Parsonage W, Elliott S, Hartas $\mathrm{J}$, et al. Evaluation of safety and immunogenicity of a group A streptococcus vaccine candidate (MJ8VAX) in a randomized clinical trial. PLoS ONE. (2018) 13:e0198658. doi: 10.1371/journal.pone.01 98658

23. Guerino MT, Postol E, Demarchi LMF, Martins CO, Mundel LR, Kalil J, et al. HLA class II transgenic mice develop a safe and long lasting immune response against StreptInCor, an anti-group A streptococcus vaccine candidate. Vaccine. (2011) 29:8250-6. doi: 10.1016/j.vaccine.2011. 08.113

24. Postol E, Alencar R, Higa FT, de Barros SF, Demarchi LMF, Kalil J, et al. StreptInCor: a candidate vaccine epitope against $S$. pyogenes infections induces protection in outbred mice. PLoS ONE. (2013) 8:e60969. doi: 10.1371/journal.pone.0060969

25. De Amicis KM, de Barros SF, Alencar RE, Postol E, Martins CD, Arcuri HA, et al. Analysis of the coverage capacity of the StreptInCor candidate vaccine against Streptococcus pyogenes. Vaccine. (2014) 32:410410. doi: 10.1016/j.vaccine.2013.08.043

26. INMETRO. Princípios das boas práticas de laboratório - BPL. Norma $N^{\circ}$ NITDICLA-035. (2011). Available online at: http://www.inmetro.gov.br/sidoq/ arquivos/Dicla/NIT/NIT-Dicla-35_02 (accessed December 11, 2020).

27. OECD Environmental Health and Safety Publications. Series on Principles of Good Laboratory Practice and Compliance Monitoring. Number 1: Principles of Good Laboratory Practice (1998). Available online at: http://www. oecd.org/officialdocuments/publicdisplaydocument/ (accessed December $11,2020)$.
28. Government Publishing Office. Good Laboratory Practice Standards (40 CFR Ch.I-Part 160). (1999). Available online at: https:/www.gpo.gov/fdsys/ pkg/CFR-1999-title40-vol16/pdf/CFR-1999-title40-vol16-part160 (accessed December 11, 2020).

29. National Research Council (US) Committee for the update of the guide for the care and use of laboratory animals. Guide for the Care and Use of Laboratory Animals. 8th ed. Washington DC: National Academies Press (2011), p. 220.

30. Postol E, Sa-Rocha LC, Sampaio RO, Demarchi L, Alencar RE, Abduch MCD, et al. Group A Streptococcus adsorbed vaccine: repeated intramuscular dose toxicity test in minipigs. Sci Rep. (2019) 9:9733. doi: 10.1038/s41598-019-46244-2

31. Hanly WC, Artwohl JE, Bennett BT. Review of polyclonal antibody production procedures in mammals and poultry. ILAR J. (1995) 37:93 doi: 10.1093/ilar.37.3.93

32. Leenaars M, Hendriksen CFM. Critical steps in the production of polyclonal and monoclonal antibodies evaluation and recommendations. Ilar J. (2005) 46:269-79. doi: 10.1093/ilar.46.3.269

33. He P, Zou YN, Hu ZY. Advances in aluminum hydroxide-based adjuvant research and its mechanism. Hum Vaccines Immunother. (2015) 11:47788. doi: 10.1080/21645515.2014.1004026

34. Seubert A, Monaci E, Pizza M, O’Hagan DT, Wack A. The adjuvants aluminum hydroxide and MF59 induce monocyte and granulocyte chemoattractants and enhance monocyte differentiation toward dendritic cells. J Immunol. (2008) 180:5402-12. doi: 10.4049/jimmunol.180.8.5402

35. $\mathrm{Lu} \mathrm{FJ,} \mathrm{HogenEsch} \mathrm{H}$. Kinetics of the inflammatory response following intramuscular injection of aluminum adjuvant. Vaccine. (2013) 31:397986. doi: 10.1016/j.vaccine.2013.05.107

36. Wang HB, Weller PF. Pivotal advance: eosinophils mediate early alum adjuvant-elicited B cell priming and IgM production. J Leukoc. (2008) 83:81721. doi: $10.1189 /$ jlb.0607392

37. Sokolovska A, Hem SL, HogenEsch H. Activation of dendritic cells and induction of CD4(+) $\mathrm{T}$ cell differentiation by aluminum-containing adjuvants. Vaccine. (2007) 25:4575-85. doi: 10.1016/j.vaccine.2007.03.045

38. Fae KC, Oshiro SE, Toubert A, Charron D, Kalil J, Guilherme L. How an autoimmune reaction triggered by molecular mimicry between streptococcal $\mathrm{M}$ protein and cardiac tissue proteins leads to heart lesions in rheumatic heart disease. J Autoimmun. (2005) 24:101-9. doi: 10.1016/j.jaut.2005.01.007

Conflict of Interest: The authors declare that the research was conducted in the absence of any commercial or financial relationships that could be construed as a potential conflict of interest.

Copyright (C) 2021 de Sá-Rocha, Demarchi, Postol, Sampaio, de Alencar, Kalil and Guilherme. This is an open-access article distributed under the terms of the Creative Commons Attribution License (CC BY). The use, distribution or reproduction in other forums is permitted, provided the original author(s) and the copyright owner(s) are credited and that the original publication in this journal is cited, in accordance with accepted academic practice. No use, distribution or reproduction is permitted which does not comply with these terms. 